\begin{tabular}{|c|c|c|c|c|}
\hline \multicolumn{5}{|c|}{$\begin{array}{l}\text { Jurnal Sistim Informasi dan Teknologi } \\
\text { https://jsisfotek. org/index.php }\end{array}$} \\
\hline 2021 & Vol. 3 & No. 3 & Hal: 108-113 & e-ISSN: 2686-3154 \\
\hline
\end{tabular}

\title{
Tingkat Korelasi Prestasi Akademik Terhadap Siswa SMP Menggunakan Metode Backpropagation
}

\author{
Nasma Yeni ${ }^{1 \bowtie}$, Yuhandri Yunus ${ }^{2}$ \\ ${ }^{1}$ SMP Negeri 3 Lengayang \\ ${ }^{2}$ Universitas Putra Indonesia YPTK Padang \\ nasmayeni74@gmai1.com
}

\begin{abstract}
Student academic achievement plays a very important role in determining the quality of a school. Student grades sometimes change every semester, there are increases and decreases. There is an assumption that students whose grades are in the previous semester will be in the next semester and vice versa. is expected to make it easier for us as educators to see the extent to which changes in student academic achievement. The data tested is the data of 60 class VII students in 2 semesters. Furthermore, it will be tested using the MatLab Application, then the results of the changes that occur will come out. The results of this study found that they did not know the value of semester 1 with the value of semester 2 TP. 2019/2020 is very good with an architectural pattern of 10-10-1 with a value of 95.3\%. So students who excel in semester 1 are likely to excel in the following semester. So that it can help the school in seeing the Correlation Level of Student Academic Achievement at SMPN 3 Lengayang.
\end{abstract}

Keywords: Neural Network (ANN), Backpropagation, Correlation, Semester Value, Software Matlab.

\begin{abstract}
Abstrak
Prestasi akademik siswa sangat berperan penting dalam penentuan kualitas dari sebuah sekolah.Nilai siswa terkadang berubah-ubah setiap semesternya, ada meningkat dan menurun. Ada anggapan bahwa siswa yang nilainya bagus disemester sebelumnya maka akan bagus juga disemester berikutnya dan begitu sebaliknya. maka diharapkan dapat memudahkan kita sebagai pendidik untuk melihat sejauh mana perubahan prestasi akademik siswa. Data yang diuji adalah data 60 siswa kelas VII di 2 semester. Selanjutnya akan diuji dengan menggunakan Aplikasi MatLab, maka akan keluar hasil perubahan yang akan terjadi. Hasil dari penelitian ini didapatkan bahwa korelasi antara nilai semester 1 dengan nilai semester 2 TP. 2019/2020 sangat baik dengan pola arsitektur 10-10-1 dengan nilai akurasi sebesar 95,3 \%. Maka siswa yang berprestasi di semester 1 berkemungkinan akan berprestasi juga disemester berikutnya.Sehingga dapat membantu pihak sekolah dalam melihat Tingkat Korelasi Prestasi Akademik Siswa di SMPN 3 Lengayang.
\end{abstract}

Kata kunci: Jaringan Syaraf Tiruan (JST), Backpropagation, Korelasi, Nilai Semester, Software Matlab.

(C) 2021 JSisfotek

\section{Pendahuluan}

Siswa merupakan insan harapan bangsa dan ujung tombak dari keberlangsungan sebuah instansi kependidikan. Tujuan utama pendidikan adalah Melahirkan orang-orang yang memiliki kemampuan dan keahlian [1]. Sangat penting bagi pemegang para kepentingan dibidang pendidikan untuk lebih meningkatkan tenaga ekstra agar pendidikan menjadi lebih maju dan menghasilkan keluaran generasi muda yang berkualitas dan dapat mewujudakan cita-cita bangsa. Nilai semester yang didapatkan akan memperlihatkan sejauhmana prestasi siswa [2].

Kualitas pendidikan mendapat perhatian luas dari semua pihak. Tingkat belajar dari rendah sampai ke tinggi harus dikonsentrasikan semaksimal mungkin untuk mencapai prestasi siswa yang terbaik. Sebagaimana tertuang dalam Pasal 1 butir 1 UndangUndang Nomor 20 Tahun 2003 tentang Sistem Pendidikan Nasional, Belajar merupakan upaya yang terencana dalam menciptakan suasana proses belajar dalam mengembangkan potensi peserta didik secara aktif. Diharapkan peserta didik memiliki kekuatan semangat diberbagai bidang diantaranya bidang kepercayaan, manajemen diri, personal, bijak, perilaku dan keahliandemi tanah air [3].

Banyak anggapan bahwa siswa yang berprestasi pada semester sebelumnya akan berprestasi juga pada semester berikutnya. Berdasarkan anggapan tersebut maka saya tertarik untuk melakukan pengujian data dengan membandingkan data nilai akademik siswa pada semester sebelumnya dengan nilai semester berikutnya, apakah betul anggapan tersebut atau tidak?. Biasaya kita hanya berandai-andai dalam menentukan nilai siswa berdasarkan kecakapannya yang didapat sebelumnya. Tapi dengan menggunakan metode Backpropagation kita akan dapat melihat berapa tingkat korelasi prestasi akademik siswa [4].

Jaringan syaraf tiruan menyerap keahlian pemikiran manusia dalam memberikan umpan balik, pekerjaan dan hasil [5]. Jaringan saraf tiruan akan diberikan sinyal input dan output serta akan menghasilkan output yang sudah diterimanya [6]. Metode 
Backpropagation adalah salah satu jaringan otak dengan kemampuan dapat merumuskan ilmu yang akan datang dan dapat melakukan prediksi [7]. JST mempunyai rasa empati tinggi dalam data, memiliki noise bias mengambil hubungan yang lengkap antar masukan dan keluaran [8].

Walaupun begitu, juga terdapat kekurangan pada metode ini, salah satunya tidak dapat dilihat secara rinci hasil prediksi didapatkan dan hasil pelatihan yang berubah-ubah. Semua ini terjadi karena metode ini tidak memperlihatkan model structural Serta jaringan syaraf tiruan dapat meproduksi perkiraan yang akurat jika keluaran yang masuk diluar jalur dalam pelatihan tidak mencukupi.

JST merupakan salah satu produksi buatan pemikiran mnusia yang bekerja mensimulasikan proses pembelajaran kedalam otak manusia. Kata buatan tersebut diartikan jaringan syaraf tiruan ini dipaparkan memakai software computer yang memiliki keahlian kerja perhitungan selama kerja belajar. Jaringan syaraf adalah gabungan input / output yang saling berhubungan dan memiliki bobot tertentu [9].

Jaringan syaraf tiruan didesain menggunakan aturan umum dengan semua model jaringan yang dimilikinya dengan konsep dasar yang sama. Tujuan yang dicapai akan berhasil ditentukan dengan arsitektur jaringan sangat, karena tidak semua masalah dapat masalah dapat diselesaikan dengan satu arsitektur.Ada 3 macam jenis arsitektur jaringan syaraf tiruan [10], yaitu jaringan lapis satu, jaringan banyak lapis dan jaringan lapis komplit.

Backpropagation adalah salah satu model jaringan syaraf tiruan yang memiliki multi layer.Sama dengan model jaringan syaraf yang lain, memiliki kinerja dalam mengenal pola yang dipakai untuk kerja pelatihan dan merangsang jaringan secara baik untuk input yang sama tapi tidak serupa kemudian dipakai dalam kinerja pelatihan [11]. Melatih jaringan dalam algoritma backpropagation terdiri dari tiga tahap diantaranya feed forward yang berasal dari pola keluaran, tingkat error pada backpropagation dan penyesuaian nilai bobot. [12]

Algoritma pembelajaran atau disebut juga dengan pelatihan JST, pelatihan dalam jaringan syaraf tiruan memasukkan beberapa contoh melakukan:

a. Seti $=1$, merupakan Inisialisasi bobot jaringan.

b. Model ke-i (merupakan sekelompok contoh belajar yang ada dalam set latihan) kemudian di inputkan ke jaringan input layer.

c. Jika hasil yang didapatkan sesuai kriteria kerja jaringan (sesuai persyaratan), untuk mendapatkanhasil tingkat aktivasi keluaran maka dapat menggunakan algoritma aplikasi, then exit.

d. untuk memperbarui bobot gunakan peraturan pembelajaran jaringan

e. Dan selanjutnya apabila Ifadalah $i=n$, then reset $\mathrm{i}=1$, Else i=i-1, ulang kelangkah 2.
Algotitma aplikasi inferensi merupakan bagian dari jaringan syaraf tiruan.Apabila dalam jaringan syaraf tiruan diinput satu contoh pelatihan, sehingga dapat dilakukan :

a. Pada lapisan input dimasukkan kasus ke dalam jaringan.

b. Menghitung tingkat aktivasi pada node-node jaringan.

c. Apabila seluruh unit keluran telah dikalkulasi dalam tingkat aktivasi, maka jika tidak exit jkembali ke langkah 2. Selanjutnya dilakukan proses exit dan failJika jaringannya tidak konstan, dipersembahkan untuk jaringan koneksi umpan maju.

Jaringan Syaraf Tiruan memiliki beberapa aplikasi sangat bagus untuk diaplikasikan apabila memiliki tingkat kemampuan yang sangat baik pada:

a. Klasifikasi, dengan caramenseleksi data masukan yang diterapkan kesalah satu bagian kelompok yang sudah ditentukan.

b. Mengelompokkan, hanya dengan sebuah bagian dari objek lain dapat menggambarkan suatu objek secara keseluruhan.

Kegiatan dengan menggunakan kecerdasan buatan diantaranya keahlian dalam membuat sistem, logika fuzzy, JST, games dan pembuatan robot [13].

pemrograman komputer adalah mata kuliah wajib disebuah program studi [14]. Aplikasi yang digunakan dalam pengujian adalah Matlab, dimana Matrix Laboratory (Matlab) adalah perangkat lunak yang pemanfaatannya menggunakan dasar matrix.

\section{Metodologi Penelitian}

Tahapan penelitian ini akan menjelaskan langkahlangkah atau tahap-tahap yang dilalui agar penelitian ini dapat terlaksana secara baik dan terstruktur serta dapat mencapai tujuan yang diinginkan. Dimulai dari mendeskripsikan (mengelompokkan) masalah, menganalisa (mencari penyebab) masalah, menentukan tujuan yang dicapai, mempelajari literatur/studi pustaka, mengumpulkan/mengambil data, Menganalisa JST, pengujian dengan algoritma Backpropagation, dan menguji hasil penelitian dengan Matlab 2018a.

Alur kerangka dari tahapan penelitian dapat dilihat di Gambar 1. 


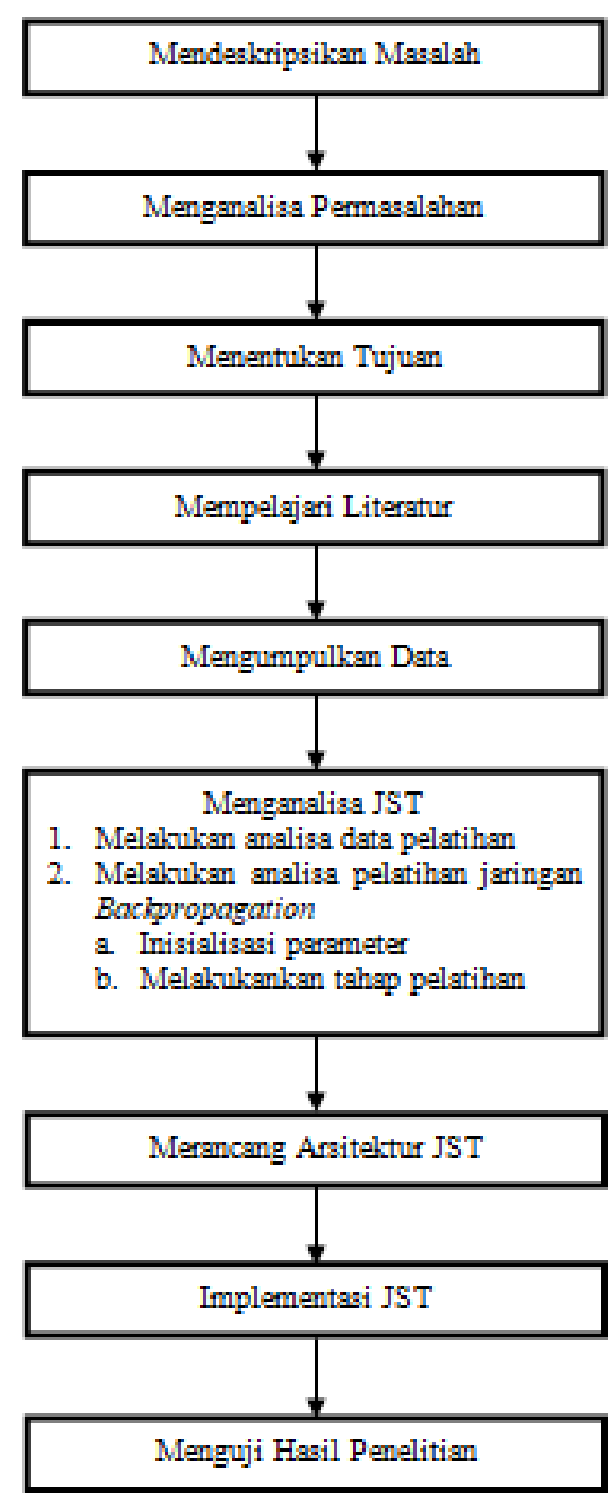

Gambar 1. Kerangka Kerja Penelitian

\subsection{Menganalisa Jaringan Syaraf Tiruan (JST)}

Menganalisa Jaringan JST dapat dilakukan apabila data yang dibutuhkan sudah terkumpul, langkahlangkah yang harus dilalui adalah sebagai berikut:

\section{Menganalisa data pelatihan}

Dilakukan untuk mengidentifikasi variable yang dibutuhkan dalam suatu penelitian. Data inilah yang merupakan objek penelitian yang menjadi perhatian penting.

\section{Melakukan analisa Pelatihan Jaringan Backpropagation}

Dilakukan analisis penyelesaian permasalahan menggunakan fungsi aktivasi sigmoid biner yang merupakan bagian dari struktur Backpropagation. Analisa pelatihan jaringan syaraf tiruan ini dibagi dalam beberapa tahap yaitu :

\section{a. Inisialisasi parameter}

Langkah ini JST diberikan masukan berupa nilai parameter yang terdiri dari 8 node input, jumlah node hidden ditentukan berdasarkan percobaan hingga didapat konfigurasi yang baik yaitu berdasarkan jumlah MSE dan MAPE yang kecil.

\section{b. Melakukan Tahap pelatihan}

Sistem jaringan syaraf tiruan dilatih menggunakan minimal $70 \%$ dari data nilai peserta didik yang telah didapat dan dilakukan proses input data dengan 8 node yang menjadi parameter input pada sistem jaringan syaraf tiruan. Target nilai yang diinginkan adalah tingkat korelasi prestasi akademik siswa.

\subsection{Merancang Struktur (JST)}

Pada tahap ini dilakukan pembentukan JST dengan menentukan jumlah keluaran neuron, jumlah layar tersembunyi, ambang batas kesalahan dan penentuan jumlah keluaran neuron. JST yang akan dibentuk adalah JST banyak layerperceptron dengan menggunakan metode Backpropagation. Pengembangan model JST menggunakan perangkat lunak MATLAB 2008a.

\subsection{Implementasi JST}

Pada tahap ini dilakukan implementasi dari rancangan Jaringan Syaraf Tiruan dengan mode pembelajaran Backpropagation kedalam sebuah prototype melalui aplikasi pemrograman MatLab. Jaringan dibentuk sesuai parameter yang sudah dirancang berikut dengan varibel input, output yang sudah ditentukan.

\subsection{Menguji Hasil Penelitian}

Pengujian System akan dilakukan pada tahap ini dengan tujuan agar dapat mengetahui system yang telah dirancang apakah berjalan dengan baik atau tidak. Dilangkah ini dilakukan pelatihan atau belajar dalam jaringan yang dibuat untuk mengenali model atau pola yang dibangun dan bertujuan agar bisa mencapai target yang ingin dicapai pada penelitian ini. Setelah mengenal pola dan dapat mencapai target yang diinginkan, selanjutnya pengujian dengan memanfaatkan keunggulan dari aplikasi MatLab2018a apakah hasil yang kita dapatkan sesuai atau sebaliknya dengan apa yang didapatkan.

\section{Hasil dan Pembahasan}

\subsection{Data}

Data apa saja yang akan diperlukan dalam program aplikasi merupakan tujuan dari analisis data. Data nilai siswa pada semester 1 dan 2 kelas 7.1, 7.2 dan 7.3 TP. 2019/2020 adalah data yang digunakan dalam penelitian ini, yang terdiri dari 10 Mata pelajaran yaitu: PKn, B.Indo, PAI, B. Ingg, MM, IPA, IPS, Senbud, Keterampilan \& Penjaskes sebagai data uji. Pada Tabel 1 disajikan data uji nilai siswa. 
Nasma Yeni, Yuhandri Yunus.

Tabel 1. Rata-rata Data Nilai Siswa Pengetahuan Semester 2 TP. 2019/2020

\begin{tabular}{|c|c|c|c|c|c|c|c|c|c|c|c|c|c|}
\hline \multirow[b]{2}{*}{ No } & \multirow[b]{2}{*}{ Nama } & \multicolumn{10}{|c|}{ Mata Pelajaran } & \multirow[t]{2}{*}{$\mathrm{Jml}$} & \multirow[t]{2}{*}{ Rata2 } \\
\hline & & PAI & PKN & B.INDO & B.INGG & MM & IPA & IPS & PJOK & $\begin{array}{l}\text { SEN. } \\
\text { BUD }\end{array}$ & $\begin{array}{l}\text { PRAK } \\
\text { ARYA }\end{array}$ & & \\
\hline 1 & Ahmad Fauzi & 75 & 75 & 76 & 83 & 75 & 75 & 80 & 78 & 90 & 78 & 785 & 78.5 \\
\hline 2 & Andika Gemilang & 75 & 73 & 76 & 80 & 75 & 78 & 75 & 80 & 85 & 76 & 773 & 77.3 \\
\hline 3 & Aulia eka Putri & 83 & 82 & 80 & 90 & 80 & 80 & 90 & 82 & 92 & 90 & 849 & 84.9 \\
\hline 4 & Chika Oksidola & 79 & 80 & 80 & 90 & 85 & 80 & 90 & 82 & 92 & 78 & 836 & 83.6 \\
\hline 5 & Dadang Heydan & 75 & 75 & 76 & 80 & 72 & 75 & 75 & 80 & 85 & 76 & 769 & 76.9 \\
\hline 6 & Danel Mahendra & 75 & 75 & 75 & 75 & 74 & 76 & 75 & 75 & 76 & 75 & 751 & 75.1 \\
\hline 7 & Dewo Julma & 75 & 65 & 76 & 84 & 75 & 75 & 90 & 80 & 85 & 76 & 781 & 78.1 \\
\hline 8 & Eyi Intan Cahyani & 80 & 70 & 80 & 85 & 78 & 80 & 90 & 86 & 85 & 88 & 831 & 83.1 \\
\hline 9 & Fitri Jamilah & 78 & 83 & 80 & 88 & 75 & 82 & 90 & 86 & 90 & 78 & 829 & 82.9 \\
\hline 10 & Flora Risti & 79 & 82 & 80 & 85 & 75 & 75 & 90 & 84 & 92 & 77 & 819 & 81.9 \\
\hline
\end{tabular}

\subsection{Hasil Normalisasi data}

Datainput harus dipresentasikan dalam bentuk numerik 0 sampai 1supaya data dapat dikenali. Maksudnya adalah jaringan menggunakan fungsi aktivasi Sigmoid Biner (logsig) dengan nilai range yang dimiliki dari 0 sampai 1. Data pelatihan sebelumnya harus melalui tahap normalisasi, adapaun data yang digunakan adalah data nilai siswa. Pada tahap normalisasi melakukan perhitungan dengan menggunakan satu contoh data latih, yaitu:

$$
\mathrm{X}^{\prime}=\frac{0.8(X-a)}{b-a}+0.1
$$

Dimana $X$ ' untuk Hasil Normalisasi Data, X untuk Data di normalisasi, a untuk Data nilai terkecil, dan b untuk Data nilai terbesar.

Tabel 2. Data Pelatihan Setelah Normalisasi

\begin{tabular}{|c|c|c|c|c|c|c|c|c|c|c|c|c|}
\hline \multirow{2}{*}{ No } & \multicolumn{10}{|c|}{ Mata Pelajaran } & \multirow[t]{2}{*}{$\mathrm{Jml}$} & \multirow[t]{2}{*}{ Rata2 } \\
\hline & $\mathrm{X} 1$ & $\mathrm{X} 2$ & $\mathrm{X} 3$ & $\mathrm{X} 4$ & $\mathrm{X} 5$ & X6 & $\mathrm{X} 7$ & $\mathrm{X} 8$ & X9 & $\mathrm{X} 10$ & & \\
\hline 1 & 0.4579 & 0.4579 & 0.4368 & 0.4579 & 0.4158 & 0.4579 & 0.4158 & 0.5211 & 0.5211 & 0.4158 & 0.195 & 0.4579 \\
\hline 2 & 0.4579 & 0.4579 & 0.4368 & 0.4579 & 0.4579 & 0.4579 & 0.5842 & 0.5211 & 0.5421 & 0.5211 & 0.275 & 0.4579 \\
\hline 3 & 0.7737 & 0.6474 & 0.5842 & 0.6263 & 0.6474 & 0.7316 & 0.8579 & 0.6263 & 0.7316 & 0.6263 & 0.74 & 0.7737 \\
\hline 4 & 0.6895 & 0.5421 & 0.5211 & 0.6053 & 0.6263 & 0.6684 & 0.7947 & 0.5421 & 0.6474 & 0.5632 & 0.585 & 0.6895 \\
\hline 5 & 0.4579 & 0.4579 & 0.4368 & 0.4579 & 0.4368 & 0.4579 & 0.4579 & 0.5842 & 0.5000 & 0.4579 & 0.23 & 0.4579 \\
\hline 6 & 0.4579 & 0.4579 & 0.4368 & 0.4579 & 0.4368 & 0.4789 & 0.4158 & 0.5421 & 0.5632 & 0.3947 & 0.215 & 0.4579 \\
\hline 7 & 0.5211 & 0.4579 & 0.4368 & 0.4579 & 0.4368 & 0.4579 & 0.5000 & 0.5211 & 0.5421 & 0.5000 & 0.26 & 0.5211 \\
\hline 8 & 0.7737 & 0.5211 & 0.5842 & 0.5000 & 0.4789 & 0.5842 & 0.7526 & 0.5632 & 0.7316 & 0.6263 & 0.565 & 0.7737 \\
\hline 9 & 0.7316 & 0.5632 & 0.5632 & 0.4579 & 0.7105 & 0.7737 & 0.7526 & 0.5632 & 0.7526 & 0.6053 & 0.65 & 0.7316 \\
\hline 10 & 0.6474 & 0.6895 & 0.5632 & 0.5000 & 0.6895 & 0.7316 & 0.7526 & 0.6263 & 0.7105 & 0.6684 & 0.675 & 0.6474 \\
\hline
\end{tabular}

3.3 Melakukan Iterasi Pertama Hingga Iterasi Terakhir pada Data Pelatihan

Tahap ini data yang telah didapatkan akan diterapkan dengan langkah-langkah algoritma backpropagation menggunakan fungsi aktivasi sigmoid. Adapun langkah-langkah pada metode backpropagation adalah

\section{a. Tahap initialization}

Merupakan tahap dimana variabel-variabel yang diperlukan dapatdiartikan, diantaranya nilai masukan, nilai bobot, serta keluaran yang diinginkan, nilai pembelajaran dan lainnya.

\section{b. Tahap activation}

Dilakukan dua kegiatan pada tahap ini yaitu menghitung nilai keluaran yang sebenarnya pada layer tersembunyi dan menghitung nilai keluaran yang sebenarnya padalayer keluaran.

c. Tahap pelatihan bobot

Dilakukan dua kegiatan pada tahap ini yaitu menghitung kesalahan gradien pada output layer dan menghitung kesalahan gradien pada hidden layer.

d. Tahap Iteration
Tahapan iteration adalah tahap terakhir yang dilakukan untuk pengujian dimana akan kembali ke tahapan yang kedua yaitu tahap activation, apabila error yang diharapkan belum juga didapatkan.

Apabila dalam bentuk matrik dan numerik maka data akan dapat dikenali dan dapat diproses menggunakan perangkat lunak. variabel atau data masukan yang digunakan sebagai analisa prosesdapat dibaca pada Tabel 3 .

Tabel 3. Keterangan Variabel Input

\begin{tabular}{llll}
\hline No & Variabel & Ket. & Nilai Input \\
\hline 1 & $\mathrm{X}_{1}$ & PAI & Nilai desimal \\
2 & $\mathrm{X}_{2}$ & PKN & Nilai desimal \\
3 & $\mathrm{X}_{3}$ & B.INDO & Nilai desimal \\
4 & $\mathrm{X}_{4}$ & B.INGG & Nilai desimal \\
5 & $\mathrm{X}_{5}$ & MM & Nilai desimal \\
6 & $\mathrm{X}_{6}$ & IPA & Nilai desimal \\
7 & $\mathrm{X}_{7}$ & IPS & Nilai desimal \\
8 & $\mathrm{X}_{8}$ & PJOK & Nilai desimal \\
9 & $\mathrm{X}_{9}$ & SEN.BUD & Nilai desimal \\
10 & $\mathrm{X}_{10}$ & PRAKARYA & Nilai desimal \\
\hline
\end{tabular}

3.4 Melakukan Pelatihan dan Menentukan Parameter Jaringan.

Metode Arsitektur Jaringan Syaraf Tiruan pada penelitian ini adalah dengan menggunakan metode 
JST backpropagationyang digunakan untuk melihat tingkat korelasi prestasi akademik siswa SMP yang terdiri dari :

a. Lapisan masukan, terdiri dari 10 simpul dan masing-masing untuk nilai rata-rata pada $\mathrm{PAI}(\mathrm{X} 1)$, PKN(X2), B.INDO(X3), B.INGG(X4), MM(X5), IPA(X6), IPS (X6), PJOK (X6), SEN.BUD (X6), PRAKARYA (X6).

b. Lapisan Output, dengan 1 simpul yaitu nilai rata (pola yang didapatkan) atau nilai (T) sebagai nilai yang menjadi predikasi untuk menghitung nilai ujian akhir sekolah.

c. Jumlah simpul yang ditentukan oleh pengguna yang disebut dengan lapisan tersembunyi.

Pada Gambar 2 dapat kita lihat bentuk Arsitektur Jaringan Syaraf Tiruan .

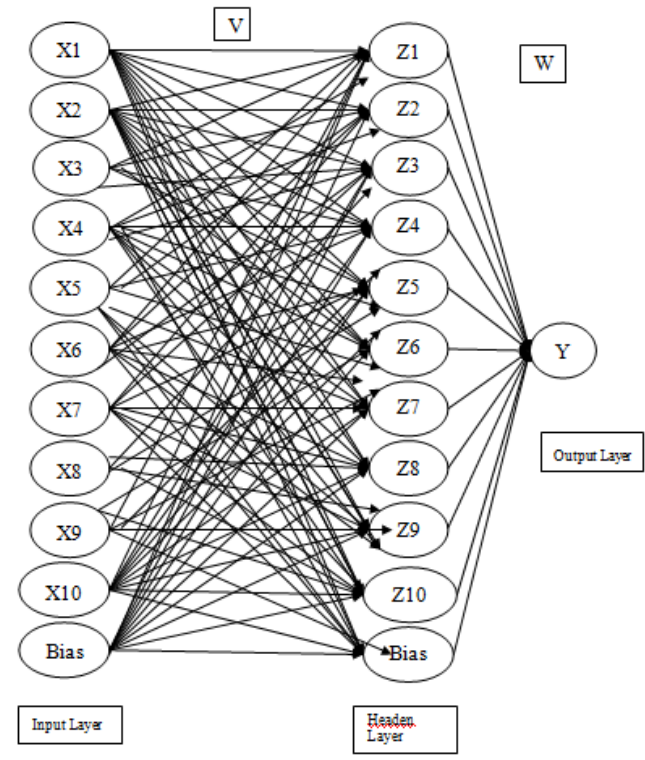

Gambar 2. Arsitektur Jaringan Backpropagation

Dimana:

$\mathrm{X}$ : masukan

$\mathrm{V}$ : bobot lapisan tersembunyi

$\mathrm{W}$ : bobot lapisan keluaran

$\mathrm{Y}$ : keluaran

Setelah didapatkan data yang telah dinormalisasikan maka bisa dilakukan proses pelatihan menggunakan aplikasi Matlab. Dalam melakukan proses pelatihan haruslah menentukan parameter jaringannya terlebih dahulu. Dalam hal ini peneliti menggunakan parameter-pamater jaringan dalam pelatihan sebegai berikut:

a. Menentukan jumlah layer tersembunyi yang akan dipakai,diawali dari jumlahnya 6, 7, 8, 9, 10 layer.

b. Epoch yang pakai antara epoch 12000 - 20000 dengan peningkatan setiap epochnya 2000.

c. Learning rate (lr) yang akandipakai dalam proses pelatihan ini adalah $0.1 ; 0.01,0.001$ dan 0.0001 . d. Target error atau goal yang akan dipakai adalah $0.1 ; 0.01,0.001$ dan 0.0001

Penentuan parameter ini nantinya akan di uji pada aplikasi matlab agar mengetahui proses pembelajaran yang terbaik dari setiap percobaan yang dilakukan.

Algoritma Backpropagation dengan fungsi aktivasi Sigmoidyang akan digunakan dalam membangun Jaringan Syaraf Tiruan, dalam proses perhitungan terhadap nilai aktual output pada hidden layer dan perhitungan nilai aktual pada output layer akan dipakai fungsi aktivasi Sigmoid.

\subsection{Menentukan Kalkulasi Error/MSE}

Mean Squared Error (MSE) adalah suatu metode untuk mengukur tingkat keakuratan dari suatu prediksi sehingga nantinya akan ditemukan nilai kesalahan yang terkecil. Adapun persamaan untuk mencari MSE adalah:

$$
\mathrm{MSE}=\frac{\sum_{i=1}^{n}(X t-F t)^{2}}{n}
$$

Dimana :

MSE : Meas Squared Error (MSE);

Xt : Nilai aktual pada waktu t;

Ft : Nilai peramalan pada waktu t;

n : Jumlah data;

\subsection{Melakukan Proses Pengujian Metode Backpropagation}

Selanjutnya melakukan pengujian metode Backpropagation setelah proses normalisasi / transformasi data. Jaringan yang dibuat pada metode backpropagation arsitektur adalah 10-10-1, dimana jumlah unit pada layer masukan / input layer ada 10, sementara jumlah unit pada layer tersembunyi / hidden layer ada 10 dan jumlah unit pada layer keluaran/output layer ada 1 layer. Pada gambar 2 arsitektur jaringan metode Backpropagation dapat dilihat yang telah digambarkan sebelumnya.

\section{Kesimpulan}

Setelah melakukan penelitian ini dengan pola arsitektur 10-10-1, maka dapat diambil kesimpulan bahwa tingkat korelasi kecocokan antara nilai semester 1 dengan semester 2 sebesar 95,3\%, maka siswa yang berprestasi di semester 1 berkemungkinan akan berprestasi juga disemester berikutnya.

\section{Daftar Rujukan}

[1] Syofneri, N., Defit, S., \& Sumijan. (2019). Implementasi Metode Backpropagation untuk Memprediksi Tingkat Kelulusan Uji Kopetensi Siswa. Jurnal Informasi dan Teknologi, 1(4) 12-17. https://doi.org/10.37034/jidt.v1i4.13

[2] Lesnussa, Y. A., Latuconsina, S., \& Persulessy, E. R. (2016). Aplikasi Jaringan Saraf Tiruan Backpropagation untuk Memprediksi Prestasi Siswa SMA (Studi kasus: Prediksi Prestasi Siswa SMAN 4 Ambon). Jurnal Matematika Integratif, 11(2), $\quad 149 \quad-\quad-160 . \quad$ DOI: https://doi.org/10.24198/jmi.v11.n2.9427.149-160 . 
[3] Zulmawati, Z. (2019). Pengaruh Strategi Proses Belajar Mengajar Terhadap Peningkatan Prestasi Belajar Siswa (Studi Pada SMP Swasta Riama Medan). SEJ (School Education Journal), $9(2)$.

DOI: https://doi.org/10.24114/sejpgsd.v9i2.13702

[4] Wanto, A. (2018). Optimasi Prediksi dengan Algoritma Backpropagation dan Conjugate Gradient Beale-Powell Restarts. Jurnal Nasional Teknologi dan Sistem Informasi, 3(3), 370-380.

[5] Masruroh., \& Mauladi, K. F. (2020). Perbandingan Metode Regresi Linear dan Neural Network Backpropagation dalam Prediksi Nilai Ujian Nasional Siswa SMP Menggunakan $\begin{array}{llll}\text { Software } & R & \text { Joutica, } & 5(1) .\end{array}$ https://doi.org/10.30736/jti.v5i1.347 .

[6] Sadli, A. (2019). Simulasi Pengenalan Karakter Menggunakan Neural Network Pada Matlab. Jurnal Sistem Informasi dan Teknologi Informasi, 7(1).

[7] Saputra, W., Tulus., Zarlis, M., Sembiring, R. W., \& Hartama D. (2017). Analysis Resilient Algorithm on Artificial Neura Network Backpropagation. International Conference on Information and Communication Technology (IconICT), Series: Journal of Physics: Conference Series, 930. DOI http://doi.org/10.1088/1742-6596/930/1/012035

[8] Apriyani, Y. (2018). Penerapan Jaringan Syaraf Tiruan Backpropagation Untuk Prediksi Nilai UN Siswa SMPN 2 Cihaurbeuti. IJCIT (Indonesian Journal on Computer and Information Technology, 3(1), 63-70.
[9] Amrin, A. (2018). Perbandingan Metode Neural Network Model Radial Basis Function dan Multilayer Perceptron Untuk Analisa Risiko Kredit Mobil. Jurnal Paradigma, 20(1), 31-38.

[10]Zola, F., Nurcahyo, G. W., \& Santony, J. (2018). Jaringan Syaraf Tiruan Menggunakan Algoritma Backpropagation Untuk Memprediksi Prestasi Siswa. Jurnal Teknologi dan Open Source, $\quad 1(1), \quad 58-72 . \quad$ DOI: http://dx.doi.org/10.36378/jtos.v1i1.12 .

[11] Yanto, M., Defit, S., \& Nurcahyo, G. W. (2015). Analisis Jaringan Syaraf Tiruan Untuk Memprediksi Jumlah Reservasi Kamar Hotel dengan Metode Backpropagation (Studi Kasus Hotel Grand Zuri Padang). Jurnal KomTekInfo, 2(1).

[12] Solikhun., Safii, M., \& Trisno, A. (2017). Jaringan Saraf Tiruan Untuk Memprediksi Tingkat Pemahaman Sisiwa Terhadap Mata pelajaran dengan Menggunakan Algoritma Backpropagation. Jurnal Sains Komputer \& Informatika (JSAKTI), 1(1)

[13]Cynthia, E. P., \& Ismanto, E. (2017). Jaringan Syaraf Tiruan Algoritma Backpropagation dalam Memprediksi Ketersediaan Komoditi Pangan Provinsi Riau. RABIT (Jurnal Teknologi dan Sistem Informasi Univrab, 2(2). DOI: https://doi.org/10.36341/rabit.v2i2.152

[14]Atina, A. (2019). Aplikasi Matlab pada Teknologi Pencitraan Medis. Jurnal Penelitian Fisika dan Terapannya, 1(1). DOI: http://doi.org/10.31851/jupiter.v1i1.3123 